\title{
Mitogen-Activated Protein Kinase Signaling Enhances Sodium Iodide Symporter Function and Efficacy of Radioiodide Therapy in Nonthyroidal Cancer Cells
}

\author{
Kyung-Ho Jung, Jin-Young Paik, Bong-Ho Ko, and Kyung-Han Lee \\ Department of Nuclear Medicine, Samsung Medical Center, Sungkyunkwan University School of Medicine, Seoul, Korea
}

\begin{abstract}
Although the success of sodium/iodide symporter (NIS) genebased cancer therapy is critically dependent on the level of radioiodide accumulation attained, recent evidence indicates that successful therapy relies not solely on NIS amount but also crucially on its functional activity. In this study, we investigated the role of kinase-linked signaling on the regulation of NIS function in cancer cells. Methods: T47D human breast cancer and PC12 rat pheochromocytoma cells were transduced with the human NIS genes via an adenoviral vector. Cells were measured for ${ }^{125} \mid$ uptake, and the effects of activation or inhibition of protein kinase $\mathrm{C}(\mathrm{PKC})$ and mitogen-activated protein (MAP) kinase pathways were evaluated. Membrane localization of NIS was evaluated by biotinylation-immunoblotting and confocal microscopy. ${ }^{131} \mathrm{I}-$ mediated cancer cell killing was evaluated by clonogenic assays. Results: NIS function was acutely reduced by short stimulation with the PKC activator phorbol 12-myristate 13-acetate and increased by its inhibition with staurosporine or prolonged phorbol 12-myristate 13-acetate exposure. Surprisingly, epidermal growth factor (EGF) caused a strong dose-dependent augmentation of radioiodide transport, accompanied by extracellular signal-regulated kinase (ERK)-1/2 activation. Both effects were completely abrogated by specific MAP kinase kinase (MEK) inhibitors, which also reduced basal NIS function. Hence, radioiodide uptake levels could differ 24-fold, depending on ERK activity. Biotinylationimmunoblotting and confocal microscopy revealed that EGF increases plasma membrane-localized NIS without affecting total cellular levels. EGF stimulation was sufficient to enhance the killing effect of ${ }^{131}$ I on the cancer cells. Conclusion: Thus, PKC and ERK signaling play important roles in the regulation of NIS function, and control of these signaling pathways may help enhance the efficacy of radioiodide cancer therapy.
\end{abstract}

Key Words: $\mathrm{Na} / \mathrm{l}$ symporter; cancer; gene therapy; radioiodide therapy

J Nucl Med 2008; 49:1966-1972

DOI: 10.2967/jnumed.108.055764

Received Jul. 8, 2008; revision accepted Aug. 27, 2008.

For correspondence or reprints contact: Kyung-Han Lee, Department of Nuclear Medicine, Samsung Medical Center, Sungkyunkwan University School of Medicine, 50 Ilwon-Dong, Kangnam-Gu, Seoul, Korea.

E-mail: khnm.lee@samsung.com

COPYRIGHT @ 2008 by the Society of Nuclear Medicine, Inc.
$\mathbf{S}$ odium/iodide symporter (NIS) gene transfer has emerged as a promising strategy for radioiodide therapy of extrathyroidal malignancies (1-5). The NIS, a plasma membrane glycoprotein, mediates active influx of iodide into cells through coupling with sodium transport down its electrochemical gradient. In thyroid cancer, endogenous NIS provides the molecular basis for the widespread application of radioiodide therapy, which has proved over the years to be a remarkably effective mode of eliminating malignant cells with minimal side effects (5). This success has instigated considerable efforts to extend the use of radioiodides to treat nonthyroid cancers via NIS gene therapy. Although some studies have shown promising results, many other endeavors have encountered difficulty in achieving sufficient radioiodine accumulation, the critical determinant of therapeutic efficacy. Therefore, it is crucial to develop methods to further augment NIS function after gene delivery if clinical radioiodide therapy of nonthyroid cancers is to be realized.

Although NIS protein quantity is an obvious factor for iodide transport capacity, accumulating evidence indicates that this is not the sole determinant and that the functional activity of the protein is also of critical importance. Despite its substantial importance, however, very little is known about the regulatory mechanisms involving NIS function. The function of sodium- and chloride-dependent neurotransmitter transporters is dynamically modulated in response to exogenous stimuli by controlling the surface targeting of the transporters (6-9). NIS transporters also need to be located at the plasma membrane to be functionally active, which is demonstrated in thyroid cells, in which thyroid-stimulating hormone (TSH) is required for membrane retention of NIS and its deprivation causes an acute decrease of iodide uptake (10). In breast cancer cells, the frequent observation of endogenously expressed NIS with deficient iodide uptake capacity (11) has been partly attributed to predominant cytosolic localization $(12,13)$. Moreover, cancer cells transduced with the NIS gene demonstrate divergent radioiodide concentrating abilities, 
which can relate to the proportion of membrane associated with NIS staining $(1,2,14)$.

Rapid alterations of surface transporter densities in response to acute stimuli occur through intracellular signaling pathways. The most extensively investigated examples are the rapid decrease of cell surface expression and function of dopamine (7), serotonin (8), and norepinephrine transporters (9) by protein kinase C (PKC) signaling. Another system that has been implicated in regulating transporter trafficking is the mitogen-activated protein (MAP) kinase cascade (15-18). This pathway transmits extracellular stimuli to regulate important biologic processes including cell growth, differentiation, migration, and survival (19), and its aberration features predominantly in cancer cells (20).

In this study, we used gene-transduced extrathyroidal cancer cells to investigate the role of PKC and MAP kinase signaling on NIS function and further evaluated the effect of MAP kinase activation with epidermal growth factor (EGF) on the efficacy of radioiodide therapy.

\section{MATERIALS AND METHODS}

\section{Cell Culture and Adenoviral NIS Gene Transduction}

T47D human breast cancer cells and PC12 rat pheochromocytoma cells (American Type Culture Collection) were maintained in RPMI 1640 medium (Gibco BRL) supplemented with 10\% fetal bovine serum, $2 \mathrm{mM}$ L-glutamine, 100 units of penicillin per milliliter, and $100 \mathrm{mg}$ of streptomycin per liter in a 5\% carbon dioxide incubator at $37^{\circ} \mathrm{C}$.

A replication-deficient human-recombinant adenovirus serotype 5 construct containing the human NIS gene and enhanced green fluorescent gene driven by cytomegalus virus promoters (Ad.NIS) was produced and propagated as previously described (21). Cells seeded the previous day were infected with Ad.NIS in medium containing $2 \%$ fetal bovine serum. A modest multiplicity of infection of 2 plaque-forming units was used to better resemble practical situations. Radioiodide uptake, immunoblots, and immunostaining experiments were performed using cells in 12-well plates, 100-mm plates, and 8-well chamber slides, respectively, $48 \mathrm{~h}$ after adenoviral infection.

\section{Radioiodide Uptake Measurements}

Radioiodide uptake was measured by incubating the cells with $74 \mathrm{kBq}$ of ${ }^{125}$ (Perkin Elmer NEN) added to the culture medium. After incubation for $1 \mathrm{~h}$ in $5 \%$ carbon dioxide at $37^{\circ} \mathrm{C}$, we rapidly washed the cells twice with ice-cold phosphate buffered saline (PBS), lysed them with $0.1 \mathrm{~N}$ sodium hydroxide, and measured them for radioactivity on a $\gamma$-counter (Wallac). ${ }^{125}$ I uptake levels were expressed as mean $\pm \mathrm{SD}$ of radioactive counts relative to that of control cells.

\section{Activation and Inhibition of PKC and MAP Kinase Pathways}

PKC was activated in Ad.NIS-infected T47D (T47D/NIS) and PC12 cells (PC12/NIS) by stimulation with $100 \mathrm{ng}$ of phorbol 12-myristate 13-acetate (PMA; Sigma) per milliliter for $15 \mathrm{~min}$. Inhibition of PKC was performed with $10 \mathrm{nM}$ staurosporine or by prolonged (6-h) exposure to $100 \mathrm{ng}$ of PMA per milliliter.

The MAP kinase pathway was activated by treatment with EGF (Invitrogen). Concentrations between 0.1 and $100 \mathrm{nM}$ and of varying durations of stimulation (up to $24 \mathrm{~h}$ ) were used. On the basis of the results of dose-dependence and time-course of ${ }^{125} \mathrm{I}$ uptake, 6-h stimulation with $10 \mathrm{nM} \mathrm{EGF}$ was used for the remaining experiments. Inhibition of the MAP kinase pathway was performed by adding $25 \mu \mathrm{M}$ of the selective MAP kinase kinase (MEK) inhibitors PD98059 or U0126 (Sigma) to the culture medium immediately before applying EGF. Inhibition of the phosphatidylinositol 3-kinase (PI3-kinase) pathway was performed by addition of $200 \mathrm{nM}$ wortmannin (Sigma).

\section{Immunoblotting of Phosphorylated Extracellular Signal-Regulated Kinase (ERK)-1/2}

Cells washed twice with ice-cold PBS were lysed with $500 \mu \mathrm{L}$ radioimmunoprecipitation assay (RIPA) buffer $(10 \mathrm{mM}$ Tris- $\mathrm{HCl}$, $\mathrm{pH} 7.5 ; 150 \mathrm{mM}$ sodium chloride; $1 \mathrm{mM}$ ethylenediaminetetraacetic acid; $0.1 \%$ sodium dodecyl sulfate [SDS]; $1 \%$ Triton X-100 [Sigma]; and $0.1 \%$ Na-deoxycholic acid) on a rocker at $4{ }^{\circ} \mathrm{C}$ for 15 min and centrifuged at $14,000 \mathrm{~g}$ for $15 \mathrm{~min}$. The supernatant was precleaned by incubation with $100 \mu \mathrm{L}$ of protein-A Sepharose bead slurry $(50 \%)$ at $4^{\circ} \mathrm{C}$ for $10 \mathrm{~min}$ on a rocker and centrifuged at $14,000 \mathrm{~g}$ at $4^{\circ} \mathrm{C}$ for $10 \mathrm{~min}$. The supernatant was incubated with $1 \mu \mathrm{L}$ of phosphor-p44/42 MAP kinase (Thr202/Tyr204) antibody (\#9101S; Cell Signaling) by gentle mixing for $2 \mathrm{~h}$ at $4^{\circ} \mathrm{C}$. This was followed by the addition of $100 \mu \mathrm{L}$ of protein-A Sepharose bead slurry $(50 \%)$ and overnight incubation at $4^{\circ} \mathrm{C}$. Each sample was washed 3 times with ice-cold RIPA buffer and centrifuged for $5 \mathrm{~s}$. Pellets were dissolved in $30 \mu \mathrm{L}$ of Laemmli $2 \times$ buffer (Glycerol $30 \%$; SDS 4\%; $12 \mathrm{mM}$ Tris- $\mathrm{HCl}, \mathrm{pH}$ 6.8; bromophenol blue) and heated for $5 \mathrm{~min}$ at $95^{\circ} \mathrm{C}$. The proteins were then separated on a $12 \%$ SDS-polyacrylamide gel and transferred to a nitrocellulose membrane. The membranes were incubated overnight at $4^{\circ} \mathrm{C}$ with the antibody against phospho-p44/42 (dilution, 1:1000) in Trisbuffered saline containing $0.5 \%$ polysorbate- 20 and $5 \%$ skim milk. Immunoreactive proteins were visualized with an enhanced chemiluminescence detection system, and protein band intensities were measured using a GS-800 calibrated densitometer and Quantity One software (Bio-Rad Laboratories).

\section{Immunoblotting of Total and Plasma Membrane NIS}

Immunoblotting for total and plasma membrane NIS protein was performed in T47D/NIS cells treated with $10 \mathrm{nM}$ EGF in the presence or absence of $25 \mu \mathrm{M}$ PD98059 for $6 \mathrm{~h}$ using whole-cell lysate and surface biotinylated protein, respectively. Cells were washed twice with ice-cold PBS/CM (PBS containing $0.1 \mathrm{mM}$ calcium chloride and $1 \mathrm{mM}$ magnesium chloride, $\mathrm{pH}$ 7.3) and incubated with EZ link NHS-Sulfo-SS-biotin ( $1 \mathrm{mg} / \mathrm{mL}$ ) in PBS/CM for $30 \mathrm{~min}$ at $4^{\circ} \mathrm{C}$. The reaction was quenched by 2 washes with cold $100 \mathrm{mM}$ glycine in PBS/CM and further incubation with 100 $\mathrm{mM}$ glycine in PBS/CM at $4^{\circ} \mathrm{C}$ for $20 \mathrm{~min}$. Cells were lysed in $500 \mu \mathrm{L}$ of RIPA buffer containing protease inhibitors $(1 \mu \mathrm{M}$ pepstatin A, $250 \mu \mathrm{M}$ phenylmethylsulfonyl fluoride, $1 \mu \mathrm{g}$ of leupeptin per milliliter, and $1 \mu \mathrm{g}$ of aprotinin per milliliter) for $1 \mathrm{~h}$ at $4^{\circ} \mathrm{C}$ with constant shaking. Lysates were centrifuged at $20,000 \mathrm{~g}$ for $30 \mathrm{~min}$ at $4^{\circ} \mathrm{C}$. A portion of the supernatant was used for total cell protein immunoblots. The remaining sample was used to obtain membrane protein by incubation with $100 \mu \mathrm{L}$ streptavidin beads for $1 \mathrm{~h}$ at room temperature. Beads were washed 3 times with RIPA buffer, and bound proteins were eluted with $50 \mu \mathrm{L}$ of Laemmli buffer (62.5 M Tris, pH 6.8; 20\% glycerol; 2\% SDS; 5\% $\beta$-mercaptoethanol; and $0.01 \%$ bromphenol blue) for $30 \mathrm{~min}$ at room temperature. Aliquots from total and biotinylated protein were analyzed by immunoblotting with a mouse monoclonal human NIS-specific antibody (dilution, 1:1000) (\#MS-1653-P1; 
Thermo Scientific), followed by incubation with a secondary antibody. Immunoreactive proteins were visualized, and band intensities were measured as described above.

\section{Immunofluorescent Localization of NIS}

T47D/NIS cells on an 8-well chamber slide were treated with $10 \mathrm{nM}$ EGF with or without $25 \mu \mathrm{M}$ PD98059 for $6 \mathrm{~h}$ and washed 3 times with ice-cold PBS/CM for 5 min. After a 20-min fixation in $2 \%$ paraformaldehyde, cells were rinsed 3 times with PBS/CM and incubated with $2 \mu \mathrm{L}$ of antihuman NIS antibody in $100 \mu \mathrm{L}$ PBS/CM for $1 \mathrm{~h}$ at room temperature. Cells were washed again 3 times with $\mathrm{PBS} / \mathrm{CM}$ and incubated with Texas red-labeled secondary antimouse antibody (Invitrogen) at room temperature for $1 \mathrm{~h}$. The slides were then mounted with an antifade 4',6-diamidino-2-phenylindole kit (Invitrogen), cover-slipped, and inspected under CLSM 2100 immunofluorescent confocal microscope (BioRad).

\section{Clonogenic Assay}

In vitro clonogenic assays were performed as described by Mandell et al. (22). In brief, T47D/NIS on 100-mm plates untreated or treated with $10 \mathrm{nM}$ EGF for $6 \mathrm{~h}$ were incubated with ${ }^{131} \mathrm{I}(0,0.74$, or $1.48 \mathrm{MBq} / \mathrm{mL})$ for $7 \mathrm{~h}$ at $37^{\circ} \mathrm{C}$. Cells were then washed twice with cold PBS, harvested with trypsinization, and seeded in 6-well plates at densities of 4,000 cells/well. After being cultured for $2 \mathrm{wk}$, cells were fixed with methanol for $2 \mathrm{~min}$ and washed twice with cold PBS. Cells were then stained with crystal violet solution (Sigma) for $2 \mathrm{~min}$, and the wells were counted for number of colonies containing 50 or more cells. The experiment was performed in hexaplicate, and results were expressed as mean $\pm \mathrm{SD}$ of percentage survival relative to control cells unexposed to ${ }^{131} \mathrm{I}$.

\section{Statistical Methods}

All ${ }^{125}$ I uptake experiments were repeated 2 or 3 separate times, and the results from a single representative experiment are presented as mean $\pm \mathrm{SD}$ of triplicate samples expressed as percentage relative to untreated control cells. Protein band intensities are presented as mean \pm SD of 3 or 4 samples per group expressed in arbitrary units. Clonogenic assay results are mean \pm SD of 6 samples per group expressed as percentage of number of colonies for cells unexposed to ${ }^{131}$ I. The Student $t$ test was used to evaluate the statistical significance between groups, and $P$ values less than 0.05 were considered significant.

\section{RESULTS}

\section{PKC Signaling Acutely Downregulates Radioiodide Uptake in Cancer Cells}

T47D and PC12 cells transduced with the NIS gene (T47D/NIS and PC12/NIS cells) displayed robust ${ }^{125} \mathrm{I}$ uptake that reached $11.5 \pm 0.6$ - and $12.0 \pm 0.2$-fold of uninfected cells, respectively (Fig. 1A). A short, 15-min incubation of T47D/NIS and PC12/NIS cells with PMA caused a rapid reduction of ${ }^{125} \mathrm{I}$ uptake to $59.7 \% \pm 3.8 \%$ and $58.3 \% \pm 2.3 \%$ of untreated control levels, respectively (Figs. 1B and 1C). In T47D/NIS cells, inhibition of PKC with staurosporine or prolonged exposure to PMA, which is known to result in PKC degradation $(18,23)$, significantly increased ${ }^{125} \mathrm{I}$ uptake to $243.5 \% \pm 6.6 \%$ and $235.8 \% \pm$ $4.9 \%$ of untreated cells, respectively. Prolonged exposure to PMA in the presence of staurosporine further increased uptake to $285.1 \% \pm 13.0 \%$ (Fig. 1B). In PC12/NIS cells, prolonged exposure to PMA alone and in combination with staurosporine significantly increased ${ }^{125}$ I uptake to $159.8 \% \pm$ $3.3 \%$ and $129.1 \% \pm 13.1 \%$, respectively (Fig. 1C).

\section{EGF Treatment Augments Radioiodide Uptake Through MAP Kinase Signaling}

Stimulation with EGF was shown to cause a substantial augmentation of ${ }^{125} \mathrm{I}$ uptake in T47D/NIS and PC12/NIS cells. The effect was dose-dependent with uptake levels reaching $379.6 \% \pm 24.0 \%$ and $311.8 \% \pm 61.1 \%$ of untreated levels for respective cell types by 6-h treatment with $10 \mathrm{nM}$ EGF (Fig. 2A). Evaluation of the time course of effect induced by $10 \mathrm{nM}$ EGF showed a significant increase by $4 \mathrm{~h}$ and peak effect at $8 \mathrm{~h}$ of stimulation (Fig. 2B). This was not, however, accompanied by any change in ${ }^{125}$ I efflux rates (Fig. 2C).

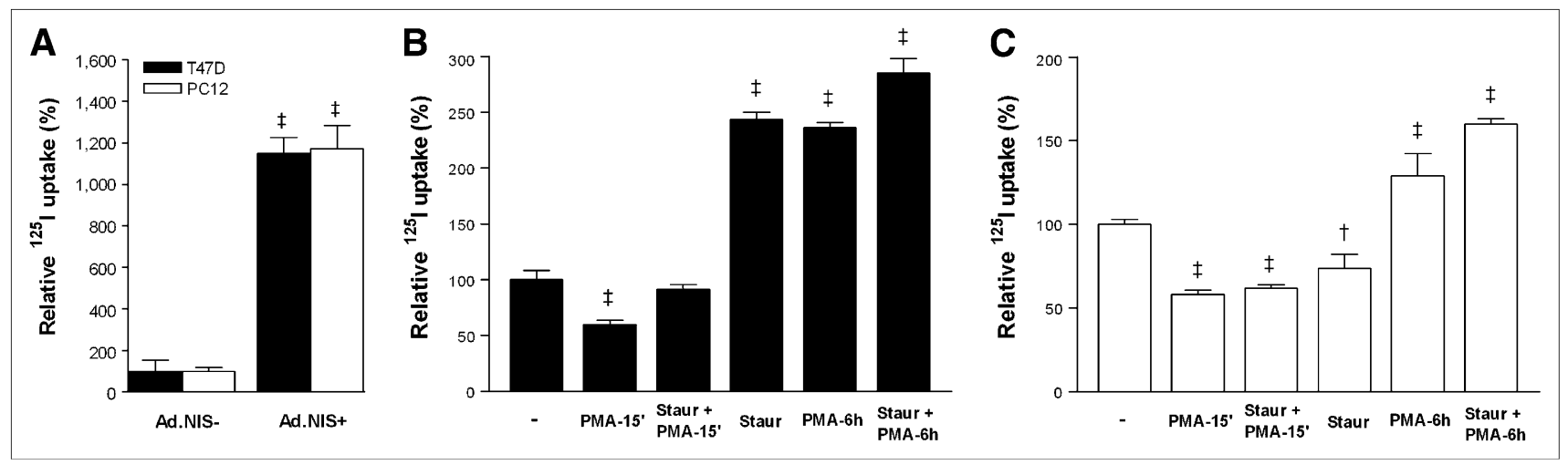

FIGURE 1. Effects of PKC signaling on cancer cell radioiodide uptake. (A) ${ }^{125}$ uptake in T47D and PC12 cancer cells before and $48 \mathrm{~h}$ after infection with Ad.NIS. Cells were incubated with $74 \mathrm{kBq}$ of ${ }^{125} \mathrm{I}$ for $1 \mathrm{~h}$ and measured for uptake levels after rapid washing. Effects of PKC activation by 15-min stimulation with $100 \mathrm{ng}$ of PMA per milliliter and PKC inhibition by $10 \mathrm{nM}$ staurosporine or 6-h exposure to $100 \mathrm{ng}$ of PMA per milliliter on ${ }^{125}$ I uptake in T47D/NIS (B) and PC12/NIS (C) cells. Data are mean \pm SD of quadruplicate samples expressed as percentage uptake relative to that of control cells, obtained from single experiment representative of 2 separate experiments. ${ }^{\dagger} P<0.005$; ${ }^{\ddagger} P<0.0001$, when compared with control cells. Staur $=$ staurosporine. 

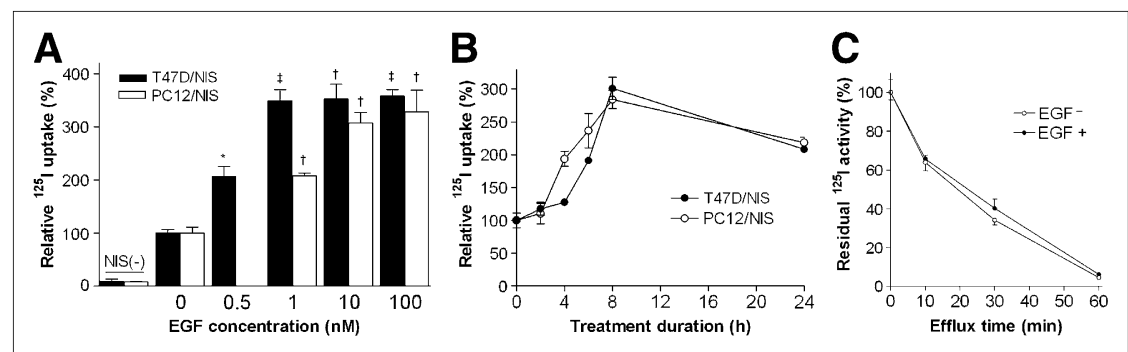

FIGURE 2. Effect of EGF treatment on cancer cell radioiodide uptake and efflux. (A) Dose-dependent augmentation of ${ }^{125}$ | uptake in T47D/NIS and PC12/NIS cells by treatment with indicated concentrations of EGF for $6 \mathrm{~h}$. (B) Time course of $10 \mathrm{nM}$ EGF-stimulated 125 uptake in T47D/NIS and PC12/NIS cells. Data are mean \pm SD of triplicate samples expressed as percentage uptake relative to untreated cells, obtained from single experiment representative of 3 separate experiments. (C) Effect of 6-h treatment with $10 \mathrm{nM}$ EGF on radioiodide retention in T47D/NIS cells. After 1-h incubation with ${ }^{125}$ I, EGF-treated (EGF+) and -untreated cells (EGF-) were rapidly washed and incubated with fresh culture medium. Radioactivity remaining in cells over time was measured and expressed as mean \pm SD of triplicate samples relative to that at time zero. ${ }^{*} P<0.001$; ${ }^{\dagger} P<0.0005$; ${ }^{\ddagger} P<0.00005$, when compared with untreated cells. NIS( -$)=$ cells uninfected with Ad.NIS.

EGF treatment of T47D/NIS and PC12/NIS cells activated the MAP kinase pathway, as assessed by significant increases in phosphorylated MAP kinase (p42- and p44ERK) levels. This activation was effectively blocked by cotreatment with the selective MEK inhibitor, PD98059 (Figs. 3A and 3B).

Using the specific MEK1/2 inhibitor U0126, we found that the blocking of ERK signaling dose-dependently decreased basal ${ }^{125}$ I uptake levels and was more pronounced for T47D/NIS and PC12/NIS cells (Figs. 4A and 4B). The status of MAP kinase signaling could thus result in up to $24.3 \pm 1.4$-fold differences in ${ }^{125}$ I uptake levels. Furthermore, MEK inhibition with PD98059 completely abrogated the effect of EGF on augmenting ${ }^{125}$ I uptake in both T47D/NIS and PC12/NIS cells (Fig. 4C). In contrast,

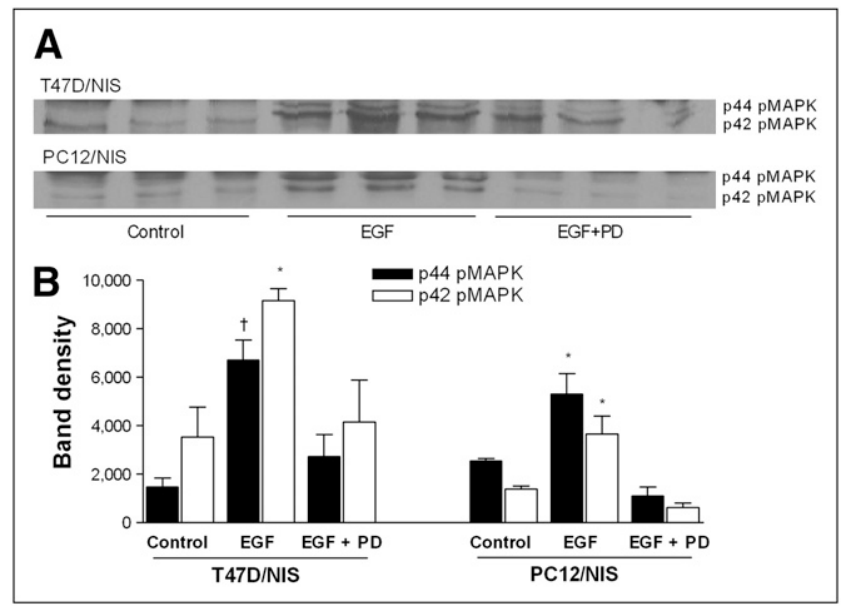

FIGURE 3. Effect of EGF treatment on ERK-1/2 activation. (A) T47D/NIS and PC12/NIS cell lysates underwent immunoprecipitation and immunoblotting with specific antibody against phosphorylated ERK-1/2 (p44 and p42 MAP kinase). Electrophoretic separation was done on $12 \%$ SDS-polyacrylamide gel. Group of cells was treated with $10 \mathrm{nM}$ EGF for $30 \mathrm{~min}$ (EGF), and separate group of cells was cotreated with $25 \mu \mathrm{M}$ of MEK inhibitor PD98059 (EGF+PD). (B) Quantitative protein band densities measured with calibrated densitometer. Data are mean \pm SD of 3 samples per group expressed in arbitrary units. ${ }^{\star} P<0.05$; ${ }^{\dagger} P<0.005$, when compared with untreated cells. the EGF effect was relatively insensitive to inhibition of the PI3-kinase pathway, with T47D/NIS cells showing less than $20 \%$ reduction of EGF-stimulated ${ }^{125}$ I uptake by $200 \mathrm{nM}$ wortmannin (data not shown).

\section{EGF Increases Membrane-Localized NIS in a MAP Kinase-Dependent Manner}

Biotinylation-immunoblot analysis revealed that EGF stimulates a significant increase in plasma membranelocalized NIS protein, and that this is effectively blocked by PD98059 (Figs. 5A and 5B). On the other hand, total cellular NIS levels were unaffected by EGF treatment with or without PD98059 (Figs. 5A and 5B).

Subcellular localization of the NIS protein by immunofluorescent confocal microscopy showed findings consistent with the immunoblot results. Although control cells showed NIS immunoreactivity distributed diffusely throughout the cytosol, cells exposed to EGF disclosed a significant shift of NIS localization to the cell surface, and this effect was reversed by PD98059 (Fig. 6A).

\section{EGF Stimulation Is Sufficient to Enhance Radioiodide- Induced Cancer Cell Killing}

When T47D/NIS cells were treated with ${ }^{131} \mathrm{I}$ for $7 \mathrm{~h}$, cells unexposed to EGF showed survival rates of $98.4 \% \pm 10.9 \%$ and $82.4 \% \pm 6.0 \%$ by 0.74 and $1.48 \mathrm{MBq}$ of radioactivity per milliliter, respectively. In comparison, exposure in advance to EGF resulted in significantly reduced survival, down to $78.2 \% \pm 8.3 \%$ and $56.0 \% \pm 8.1 \%$ with respective ${ }^{131} \mathrm{I}$ doses (Fig. 6B). The reduced survival indicates that more efficient cancer cell killing can be achieved by enhancing iodide transport capacity through EGF-induced MAP kinase activation.

\section{DISCUSSION}

The use of NIS as a therapeutic gene has emerged as a promising strategy for targeted radiotherapy of cancer. Indeed, the ability to concentrate radioiodides has been successfully transferred through NIS gene therapy in various extrathyroidal cancer cells, including breast, liver, prostate, and neuroendocrine tumors (1-5). However, despite endeavors to maximize NIS transcripts with high viral vector 


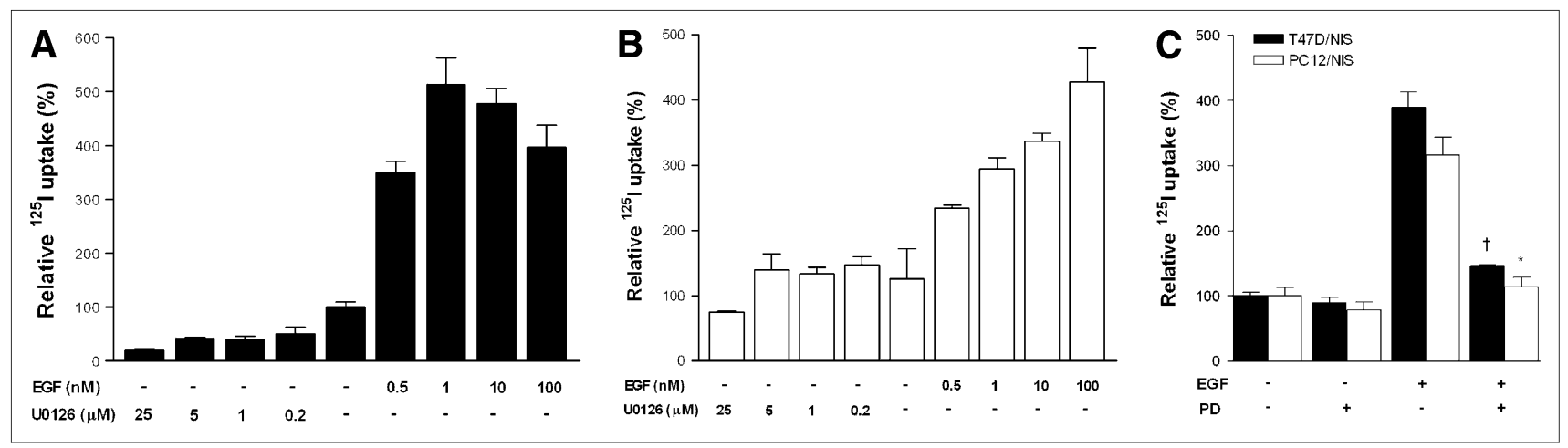

FIGURE 4. Effect of MEK inhibitors on EGF-stimulated radioiodide uptake. Effects of graded concentrations of EGF or selective MEK1/2 inhibitor U0126 (25 $\mu \mathrm{M})$ on ${ }^{125}$ I uptake in T47D/NIS (A) and PC12/NIS (B) cells are demonstrated. (C) Effect of MEK inhibitor PD98059 $(25 \mu \mathrm{M})$ on ${ }^{125}$ I uptake in T47D/NIS and PC12/NIS cells with or without 6 -h treatment with $10 \mathrm{nM}$ EGF is shown. All data are mean \pm SD of triplicate samples expressed as percentage uptake relative to untreated cells, obtained from single experiment representative of 2 or 3 separate experiments. ${ }^{*} P<0.0005 ;{ }^{\dagger} P<0.0001$, compared with cells treated with EGF without $P D 98059$.

titers and potent promoters, therapeutic efficacy can be limited because of the insufficient levels of radioiodide accumulation attained. Therefore, a better understanding of the mechanisms that regulate the functional activity of NIS transporters will be crucial for the widespread application of radioiodide-based cancer therapies.

Using NIS gene-transduced cancer cells, we demonstrated that NIS function is rapidly decreased by PKC activation and increased by its inhibition. Conversely, radioiodide uptake was substantially augmented by MAP kinase activation with EGF, whereas it was dose-dependently attenuated by MEK inhibitors. Both EGF-induced ERK-1/2 activation and radioiodide uptake enhancement were completely abrogated by MEK inhibition. Further investigation revealed that EGF increases plasma membrane-localized NIS without affecting total cell levels. Importantly, EGFstimulated enhancement of NIS function was sufficient to render the cancer cells more susceptible to treatment with a radioiodide.

PKC-mediated acute downregulation of functional activity is well established for several neurotransmitter transporters (6-9). Phorbol esters such as PMA rapidly activate PKCs by mimicking the action of endogenous diacylglycerol. On the other hand, when cells are exposed to PMA for prolonged durations, PKC signaling is downregulated by proteolytic degradation of the enzyme (23). In our study, radioiodide uptake was acutely decreased by PMA but was increased when the exposure was prolonged and was also increased by the PKC inhibitor staurosporine. These findings demonstrate that $\mathrm{PKC}$ signaling is a negative regulator of NIS function.

In search of a signaling pathway that upregulates NIS function, we tested the effect of treatment with EGF, a wellknown activator of major intracellular kinase cascades. As a result, we found that EGF promotes substantial augmentation of radioiodide uptake through MAP kinase but not PI3-kinase pathways. MAP kinases are evolutionary conserved enzymes that transmit signals from cell surface receptors to critical intracellular targets (19). Among MAP kinases, p38 MAP kinase has been shown to be involved in maintaining normal basal expression of serotonin transporters (17) and promoting the activation of norepinephrine transporters (18). ERK-1/2 MAP kinase has been implicated in regulating the transport capacity of dopamine transporters. In striatal synaptosomes and HEK293 cells, blocking of constitutively active MAP kinase with MEK inhibitors resulted in decreased dopamine uptake (15). MEK inhibitors have also been shown to reduce substrate uptake in COS cells transiently expressing dopamine transporters (16). Our results indicate that NIS function may be
FIGURE 5. Immunoblots of membrane and total NIS protein. (A) Cell surface protein was prepared by biotinylation of T47D/NIS cells with $1 \mathrm{mg}$ of sulfo-NHS-SS-biotin per milliliter and precipitation of surfacebiotinylated protein with streptavidinagarose beads. Cell surface and total NIS protein were separated on $10 \%$ SDSpolyacrylamide gel, electrotransferred, and immunoblotted with antihuman NIS antibody. (B) Quantitative NIS protein band densities were measured with calibrated densitometer. Data are mean \pm SD of 4 samples per group expressed in arbitrary units. EGF $=$ cells treated with $10 \mathrm{nM}$ EGF for $6 \mathrm{~h}$; EGF+PD = cells treated with EGF in presence of $25 \mu \mathrm{M}$ PD98059.
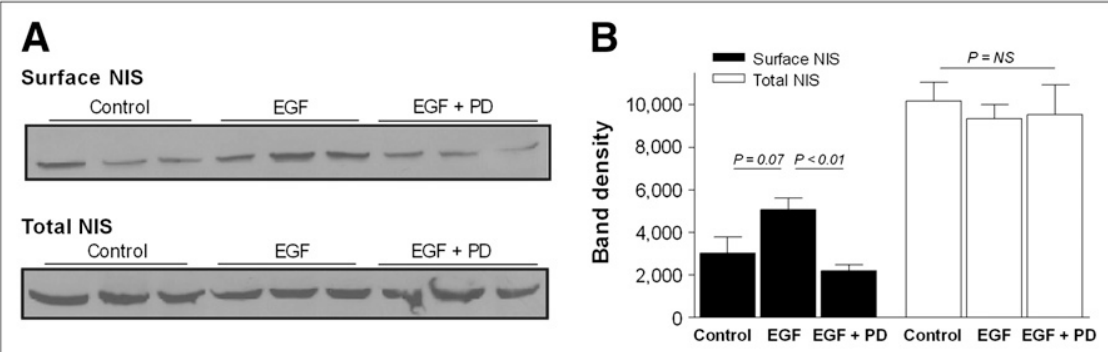


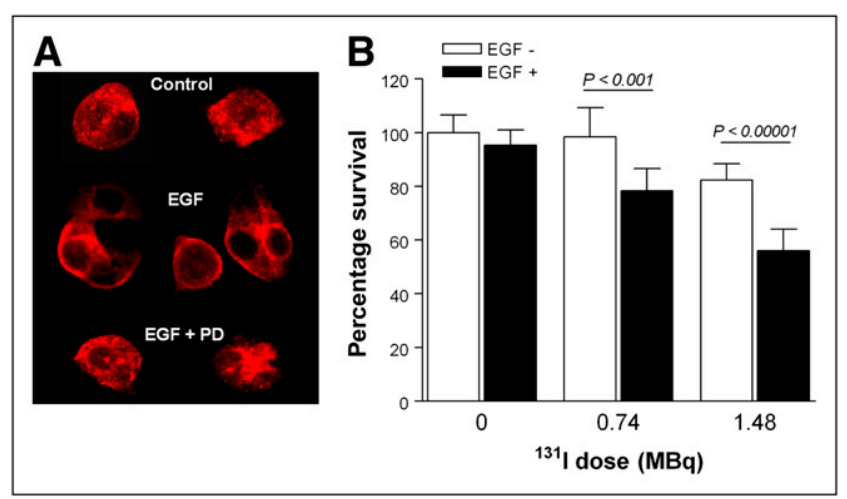

FIGURE 6. (A) Immunofluorescent confocal microscopic localization of NIS protein. T47D/NIS cells grown on 8-well chamber slide were fixed in $2 \%$ paraformaldehyde and sequentially incubated with antihuman NIS antibody and Texas red-labeled secondary antibody. NIS localization was visually assessed under fluorescent confocal microscope (magnification, $\times 1200$ ). EGF $=$ cells treated with $10 \mathrm{nM}$ EGF for $6 \mathrm{~h}$; $\mathrm{EGF}+\mathrm{PD}=$ cells treated with EGF in presence of $25 \mu \mathrm{M}$ PD98059. (B) Effect of EGF on survival rate of ${ }^{131}$ I-treated cancer cells. T47D/NIS cells treated with $10 \mathrm{nM}$ EGF for $6 \mathrm{~h}$ $(E G F+)$ were compared with control cells (EGF-) for killing effect of exposure to $0,0.74$, or $1.48 \mathrm{MBq}$ of ${ }^{131}$ I per milliliter for $7 \mathrm{~h}$. Clonogenic assays were performed by seeding irradiated cells into 6 -well plates at densities of 4,000 cells per well. Cells were fixed with methanol and stained with crystal violet, and number of colonies with 50 or more cells was counted after cells were cultured for $2 \mathrm{wk}$. Data are mean \pm SD of 6 samples per group expressed as percentage of number of colonies for cells unexposed to ${ }^{131} \mathrm{I}$.

regulated in a similar fashion. U0126 dose-dependently reduced basal radioiodide uptake, and PD98059 completely abolished EGF-stimulated uptake using concentrations that inhibit phosphorylation of ERK-1/2 MAP kinase. Taken together, these findings indicate that PKC and ERK pathways may play important roles in regulating NIS function, albeit in opposite directions. The results further show EGF treatment to be an effective means to augment NIS-mediated transport activity through MAP kinase activation.

In thyroid cells, NIS transcription and function are regulated quite differently from how they are regulated in nonthyroidal cells, and it is, therefore, unclear how ERK or PKC signaling may influence endogenously expressed NIS function. However, transcriptional expression of NIS in the thyroid is regulated by various stimuli, including TSH, which augments NIS expression via cyclic adenosine monophosphate signaling and downstream pathways that include PKA, ERK MAP kinase, and p38 MAP kinase (24). TSH also stimulates plasma membrane localization of NIS (24), suggesting that similar signaling pathways may also be involved in posttranscriptional regulation of thyroidal NIS function. Further studies, however, will be needed to clarify the effects of ERK and PKC signaling on endogenously expressed NIS function in cells, for example, in the thyroid.

The functional activity of transporters can be controlled by altering their surface presentation. For several neurotrans- mitter transporters, rapid functional regulations in response to acute stimuli occur via trafficking-dependent mechanisms that alter plasma membrane expression. Using immunoblots of membrane-impermeable biotin-bound protein and confocal microscopy to distinguish membrane from intracellular protein, we showed that EGF stimulated a significant increase of plasma membrane-localized NIS. Hence, the effect of EGF in facilitating iodide transport is due at least in part to upregulated surface NIS presentation, which may occur through increased redistribution to the plasma membrane, decreased internalization from the membrane, or both. The precise mechanism through which EGF may modulate membrane targeting of NIS is not clear. However, because a common posttranscriptional mechanism for modulating the subcellular localization and function of many transporters involves glycosylation and phosphorylation processes $(8)$, it is possible that similar processes may be in operation for regulating NIS function. Our findings underscore the importance of subcellular localization on NIS function, supporting recent observations in which iodide uptake was greater for cancer cells with predominantly membrane-associated immunostaining $(1,2)$ and NIS proteins with dissimilar surfacetargeting properties displayed disparate iodide accumulating abilities (14).

Importantly, treatment with EGF was sufficient to enhance the killing effect of radioiodides on the cancer cells. This was achieved even though EGF-enhanced radioiodide uptake was unaccompanied by a reduction in efflux rate. Although poor cellular radioiodide retention is generally considered an obstacle for the efficacy of NIS gene-mediated cancer therapy, several lines of evidence suggest that maximizing transport activity to recapture effluent radioiodides could be a solution $(2,3)$. The ability of cells to actively take up iodide via NIS gene delivery provides a unique strategy for selective destruction of cancer cells with ${ }^{131} \mathrm{I}$. The findings of this study raise the possibility that ERK-modulated NIS function may provide a feasible way to attain radioactivity accumulation sufficient to allow cancer regression with clinically realistic doses of ${ }^{131} \mathrm{I}$. This possibility will need to be further verified by animal studies that test the effects of stimulating or inhibiting EGF signaling on the efficacy of radioiodide cancer therapy in vivo.

\section{CONCLUSION}

Our results show that PKC and ERK signaling could have central roles in regulating membrane localization and the iodide transport capacity of NIS and suggest that appropriate control of these pathways through methods such as EGF-induced ERK activation may help enhance the efficacy of NIS gene-mediated radioiodide cancer therapy.

\section{ACKNOWLEDGMENTS}

This study was supported by the Korea Science and Engineering Foundation (KOSEF) grant funded by the Korean government (MOST), \# M20709000131-07B0900- 
13110. This work was presented in part at the Joint Molecular Imaging Conference, Providence, Rhode Island, September 8-11, 2007.

\section{REFERENCES}

1. Dwyer RM, Bergert ER, O'Connor MK, Gendler SJ, Morris JC. In vivo radioiodide imaging and treatment of breast cancer xenografts after MUC1-driven expression of the sodium iodide symporter. Clin Cancer Res. 2005;11:1483-1489.

2. Willhauck MJ, Sharif Samani BR, Klutz K, et al. Alpha-fetoprotein promotertargeted sodium iodide symporter gene therapy of hepatocellular carcinoma. Gene Ther. 2008;15:214-223.

3. Faivre J, Clerc J, Gérolami R, et al. Long-term radioiodine retention and regression of liver cancer after sodium iodide symporter gene transfer in wistar rats. Cancer Res. 2004;64:8045-8051.

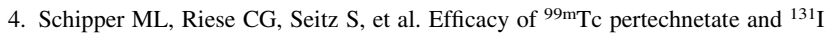
radioisotope therapy in sodium/iodide symporter (NIS)-expressing neuroendocrine tumors in vivo. Eur J Nucl Med Mol Imaging. 2007;34:638-650.

5. Riesco-Eizaguirre G, Santisteban P. A perspective view of sodium iodide symporter research and its clinical implications. Eur J Endocrinol. 2006;155:495-512.

6. Melikian HE. Neurotransmitter transporter trafficking: endocytosis, recycling, and regulation. Pharmacol Ther. 2004;104:17-27.

7. Vaughan RA, Huff RA, Uhl GR, Kuhar MJ. Protein kinase C-mediated phosphorylation and functional regulation of dopamine transporters in striatal synaptosomes. J Biol Chem. 1997;272:15541-15546.

8. Ramamoorthy S, Blakely RD. Phosphorylation and sequestration of serotonin transporters differentially modulated by psychostimulants. Science. 1999;285: 763-766.

9. Jayanthi LD, Annamalai B, Samuvel DJ, Gether U, Ramamoorthy S. Phosphorylation of the norepinephrine transporter at threonine 258 and serine 259 is linked to protein kinase C-mediated transporter internalization. J Biol Chem. 2006;281:23326-23340.

10. Riedel C, Levy O, Carrasco N. Post-transcriptional regulation of the sodium/ iodide symporter by thyrotropin. J Biol Chem. 2001;276:21458-21463.

11. Kogai T, Schultz JJ, Johnson LS, Huang M, Brent GA. Retinoic acid induces sodium/iodide symporter gene expression and radioiodide uptake in the MCF-7 breast cancer cell line. Proc Natl Acad Sci USA. 2000;97:8519-8524.
12. Arturi F, Ferretti E, Presta I, et al. Regulation of iodide uptake and sodium/iodide symporter expression in the MCF-7 human breast cancer cell line. J Clin Endocrinol Metab. 2005;90:2321-2326.

13. Knostman KA, McCubrey JA, Morrison CD, Zhang Z, Capen CC, Jhiang SM. $\mathrm{PI} 3 \mathrm{~K}$ activation is associated with intracellular sodium/iodide symporter protein expression in breast cancer. BMC Cancer. 2007;7:137.

14. Zhang Z, Liu YY, Jhiang SM. Cell surface targeting accounts for the difference in iodide uptake activity between human $\mathrm{Na}+/ \mathrm{I}-$ symporter and rat $\mathrm{Na}+/ \mathrm{I}-$ symporter. J Clin Endocrinol Metab. 2005;90:6131-6140.

15. Morón JA, Zakharova I, Ferrer JV, et al. Mitogen-activated protein kinase regulates dopamine transporter surface expression and dopamine transport capacity. J Neurosci. 2003;23:8480-8488.

16. Lin Z, Zhang PW, Zhu X, et al. Phosphatidylinositol 3-kinase, protein kinase $\mathrm{C}$, and MEK1/2 kinase regulation of dopamine transporters (DAT) require N-terminal DAT phosphoacceptor sites. J Biol Chem. 2003;278:20162-20170.

17. Samuvel DJ, Jayanthi LD, Bhat NR, Ramamoorthy S. A role for p38 mitogenactivated protein kinase in the regulation of the serotonin transporter: evidence for distinct cellular mechanisms involved in transporter surface expression. J Neurosci. 2005;25:29-41.

18. Apparsundaram S, Sung U, Price RD, Blakely RD. Trafficking-dependent and -independent pathways of neurotransmitter transporter regulation differentially involving p38 mitogen-activated protein kinase revealed in studies of insulin modulation of norepinephrine transport in SK-N-SH cells. J Pharmacol Exp Ther. 2001;299:666-677.

19. Chang L, Karin M. Mammalian MAP kinas signaling cascades. Nature. 2001;410:37-40.

20. Sebolt-Leopold JS, Herrera R. Targeting the mitogen-activated protein kinase cascade to treat cancer. Nat Rev Cancer. 2004;4:937-947.

21. Lee KH, Kim HK, Paik JY, et al. Accuracy of myocardial sodium/iodide symporter gene expression imaging with radioiodide: evaluation with a dualgene adenovirus vector. $J$ Nucl Med. 2005;46:652-657.

22. Mandell RB, Mandell LZ, Link CJ Jr. Radioisotope concentrator gene therapy using the sodium/iodide symporter gene. Cancer Res. 1999;59:661-668.

23. Huang FL, Yoshida Y, Chuna-Melo JR, Beaven MA, Huang K-P. Differential down-regulation of protein kinase C isozymes. J Biol Chem. 1989;264:42384243.

24. Kogai T, Taki K, Brent GA. Enhancement of sodium/iodide symporter expression in thyroid and breast cancer. Endocr Relat Cancer. 2006;13:797-826. 